\title{
4
}

\section{RETRACTED ARTICLES - THE SCIENTIFIC VERSION OF FAKE NEWS}

\author{
Judit Bar-Ilan and Gali Halevi
}

\section{Introduction}

Scientific advancements are gradual. "Standing on the shoulders of Giants" a well-known phrase by Newton ${ }^{1}$ refers to the scientific process wherein each paper reporting on new findings enables the scientific community to advance knowledge further by building upon previous discoveries. The purpose of scientific journals and publishing has always been to function as a reliable, vetted source for science to be shared and advanced. As a part of this responsibility, scientific journal publishers have safeguards in place to ensure that content is indeed original, reliable, and reproducible, thus keeping the scientific integrity intact. One of the main vehicles used by the scientific publishing community to ensure scientific truthfulness is the peer review process. Peer review is a practice by which each article submitted to a journal is securitized by at least two reviewers from the same field of investigation. These reviewers are always anonymous and oftentimes do not know who the authors are. These measures are specifically taken to ensure that the review is unbiased and focused on the articles and their findings. The main task of the reviewers is to verify the originality, quality, and integrity of each and every paper and examine it for accuracy of data, analysis, findings, conclusions, and more. Although reviewers can recommend major or minor revisions, they also have the ability to reject papers if they are found to be unreliable for whatever reason (Biagioli, Kenney, Martin, \& Walsh, 2018; Bozzo, Bali, Evaniew, \& Ghert, 2017; Nicholas et al., 2015).

However, despite of this rigorous process, papers are regularly retracted from journals due to a variety of reasons (Budd, Sievert, Schultz, \& Scoville, 1999; Cokol, Ozbay, \& Rodriguez-Esteban, 2008; Fang, Steen, \& Casadevall, 2012; Steen, 2010, 2011). There are times when the reason for retraction might be simple and easily correctable (Bar-Ilan \& Halevi, 2018; Budd, Sievert, \& Schultz, 
1998; Halevi \& Bar-Ilan, 2016; Williams \& Wager, 2013). These types of retractions occur due to administrative errors, errors in references, or copy editing mistakes not identified in time to be corrected prior to publication that result in the paper being retracted and a retraction notice issued. In most cases, these articles are corrected and then re-published. Yet, there are much more serious types of retractions; especially those that were triggered due to data falsification, manipulation of results, unethical use of subjects, plagiarism, and more (Almeida, de Albuquerque Rocha, Catelani, Fontes-Pereira, \& Vasconcelos, 2015; Corbyn, 2012; Fang \& Casadevall, 2011; Inoue \& Muto, 2016; Noyori \& Richmond, 2013).

In the medical and biomedical arenas, scientific retractions pulled from the literature due to ethical issues and containing erroneous, or even fabricated data, analysis, and findings should be carefully examined due to the enormous negative impact they have on future medical practices and, more importantly, human lives. In this chapter, we chose to focus on retracted articles in the medical and biomedical fields and demonstrate how they impacted, and in some cases, continue to impact the medical community and society. To illustrate the gravity of retracted articles in the medical arena and the potential of putting patients at risk, a paper by G. Steen (2011) evaluated over 180 retracted primary papers and 851 secondary ones that described the results of trials conducted on over 28,000 human subjects. Primary articles were considered those that were originally retracted, whereas secondary ones were those citing the original retracted articles, basing their data collection, methods, or analysis on them. The analysis showed that 70 papers that were retracted due to fraud, treated more patients per study than those retracted because of errors. This paper also found that these articles were cited over 5,000 times and the citations were mostly research related, meaning that ideas expressed in fraudulent papers influenced consequent research and patients enrolled in their studies. Therefore, incorrect or fraudulent information reported in medical studies and publications can harm patients directly due to continuous citations, use of methods, treatments, or ideas taken from the culprit publication.

There are several very famous cases of such retractions that reached the news media and created a public stir due to their gravity. These include the 1998 article by Dr. Wakefield in the Lancet that suggested that the combined vaccine for measles, mumps, and rubella can cause autism in children. This article - retracted in 2010 due to faulty methods and financial conflicts of the author - still, to this day, remains very influential as parents and anti-vaccine groups are reluctant to vaccinate children, which in turn caused more cases of these diseases to be detected (Facts about the Measles Outbreak, 2015). Other famous cases include Dr. Drasee, a Harvard Medical School heart researcher who fabricated the bulk of his heart research with over 100 publications retracted due to fraudulent data (Broad, 1983) or Dr. Straus, a cancer researcher, who was accused of falsifying research results, reporting on unqualified patients, administrating falsified drug dosages (Upi, 1982), and not complying with consent rules. 
In addition to these high-profile cases, retractions in the medical and biomedical fields happen regularly, and although they are mostly not life-threating, the fact that they are continuously cited in the medical literature and being shared as legitimate research can present health-related threats even years after retraction.

\section{Data sources and collection}

To examine the characteristics and impact of medical and biomedical retracted papers we used the Retraction Watch Database ('Retraction Watch Database', n.d.) curated by Adam Marcus and Ivan Oransky, the owners of "Retraction Watch" ('Retraction Watch Database', n.d.), a blog dedicated to the listing and flagging of retracted articles across scientific disciplines. Our previous work on studying retracted articles has enabled us to have access to the data curated in the database, which includes over 17,000 retracted articles, retraction notices, and reasons for retraction. The data also included valuable metadata, including author/s name/s, journal title, publisher, year, and discipline. Thanks to the disciplinary classification within the database we were able to retrieve all the medical and biomedical retracted articles published between 2010 and 2014 and retracted before 2017. Our dataset included 1,294 research articles in these areas.

The main reason for this selection was our aim to track more recent retracted articles in these fields in order to be able to monitor social media attention. The use of social media to share, discuss, or promote research is a recent phenomenon. In the early days of social media, the vast majority of its use was for personal purposes. Yet, in the past decade, more and more scientists are using social media such as Twitter and Instagram to promote their research, network with colleagues, and discuss various topics via these tools. The social media life of retracted articles was one of our main interests, because such discussions do not stay within the scientific realm - they involve lay people who follow these scientists or doctors and take an active part in sharing and discussing them. Therefore, in order to be able to track social media indicators we selected articles that were published when social media was in wide use scientists. We also collected citations counts, which are mostly scientific indicators of impact. All data, including citations, were collected in February 2019 to ensure that enough time lapsed after the retraction during which citations would appear in the scientific literature and other indicators such as readership and social media mentions would also be evident on the various platforms.

To account for both the scientific and public impact of retracted articles, we used several tools to count pre- and post-retraction citations, social media mentions, and readership counts for the retracted articles. Citations, social media and readership data were collected in February 2019. Since there is usually a time gap between the publication date and the retraction date, it is important to examine citations and attention to the article pre- and post-retraction. Although scientific citations to articles pre-retraction is an acceptable phenomenon, such citations post-retraction is worrying and bears the question why would scientists keep 
citing a retracted paper? In some cases, the citation is negative; meaning that the scientists cite the retraction in order to give an example of bad science or to enforce results that contradict retracted ones. Yet, often we also see valid, positive citations completely ignoring the fact that the paper was pulled out of the literature (Bar-Ilan \& Halevi, 2017). Although citations are considered scientific impact, readership, for example, can be a sign of both scientific and social impact since there is no telling who precisely reads these articles. Despite publishers retracting articles and issuing an appropriate notice to that affect, preprints of articles can be found in repositories and are freely available. These versions do not include the retraction notice and their readers might not be aware of the faults that led to their retraction. In addition, we also found that retracted articles become Open Access on publishers' platforms (Bar-Ilan \& Halevi, 2017; BarIlan \& Halevi, 2018). That means that they are free for readers who do not need paid subscriptions to read them. Despite the fact that they are clearly marked as "Retracted", their free availability means that they continue to be read and shared post-retraction, which presents a real problem relating to the truthfulness of such content.

Unlike citations, social media shares and mentions also represent the impact science has on the public. According to Pew research, Facebook and Twitter are quickly becoming major sources for scientific and medical information (Greenwood, Perrin, \& Duggan, 2016). Therefore, falsified, untruthful science becomes a real threat to public health when shared online via social networks and sometimes by news media outlets. The main problem with social shares is that they are so much more difficult to track and correct. Once an article becomes the focus of positive or negative attention, a formal retraction might not have the effect it needs to have to change people's perceptions the way it does with the scientific community. Although the news media might correct themselves and announce "bad science" once it's publicized, that might not happen fast enough or in an effective way that will also change public perception accordingly.

In order to report on both facets, scientific and social impact of retracted articles, we used the citation database Scopus to track citations of retracted articles both prior and after retraction. Scopus is a comprehensive database that indexes millions of articles across numerous scientific disciplines. The main advantage of using Scopus to track citations is that its metadata provides citations by year and allows one to see citations pre-retraction and later on post-retraction. This is an important piece of the puzzle as it allows us to see how many citations a retracted article receives after it is removed from the literature.

To examine social and news media attention to retracted articles as well as readership counts, we used the PlumX platform and data from Altmetric.com both aggregators of altmetric indicators. Altmetrics is a general term used to describe "alternative metrics" in science. The traditional scientific metrics are citations, whereas altmetrics include other indicators such as readership, downloads, social media mentions, and more. The aggregators track article mentions in a variety of social media outlets such as Twitter and Facebook, blogs, and 
more. In addition, they track articles that were mentioned in the news media and also count the number of times they were read on Reddit and others. In addition, we also looked at readership on Mendeley, a well-known scientific network that allows researchers to save and share scientific papers. Data aggregators track mentions by identifiers, mainly by the Digital Object Identifier (DOI) link. PlumX displays these metrics on an article dashboard on which one can read the actual comments, news articles, and blog entries. Altmetric also links to the text of blogs and displays the text of tweets. This, in turn, allowed us to examine the tone and content of these mentions for a small subset of retracted articles, thus, enabling us to judge whether the impact of these retracted articles is negatively or positively persistent post-retraction. Mendeley readership counts were collected directly from Mendeley. For data collection from Mendeley and Altmetric.com we used Mike Thelwall's free tool The Webometric Analyst (http://lexiurl.wlv. ac.uk/).

\section{Some characteristics}

\section{Where are retractions coming from?}

In order to track the geographical origin of the retracted articles we used the affiliation country of the authors. Each published article has to have the author name and his/her affiliation, which includes the country. This information was used in our analysis to track the countries from which the authors of retracted articles originate. It should be noted that each article in our dataset of 1,294 papers includes more than one author. The vast majority of scientific articles are published in collaboration where teams of scientists research and publish their results together. Many times, these are international collaborations and publications therefore include authors from several countries. Our map was constructed out of all the countries that appear in the articles; therefore, an article in the database with multiple authors from different countries is assigned to all countries. As can be seen from the map (Figure 4.1), the majority of retracted articles in our dataset originate from the United States (341), China (309), India (115), and Japan (68).

One of the strengths of the Retraction Watch Data Base is that it also extracts the reasons for retractions and categorizes them into more than 70 categories. In most cases, more than one category is assigned to each article. Our analysis showed that retracted articles originating from the United States were mostly retracted because of duplication/manipulation of images as well as falsification/ fabrication of data. Chinese papers were mostly retracted due to fake peer review, which was discovered by an investigation by the journal or plagiarism of the article. Indian papers were mostly retracted because of plagiarism, whereas Japanese papers were retracted mostly because of unreliable results and data fabrication/falsification. An interesting article published in 2017 (Fanelli, Costas, Fang, Casadevall, \& Bik, 2017) provides and overview of the main reasons why 
52 Judit Bar-Ilan \& Gali Halevi
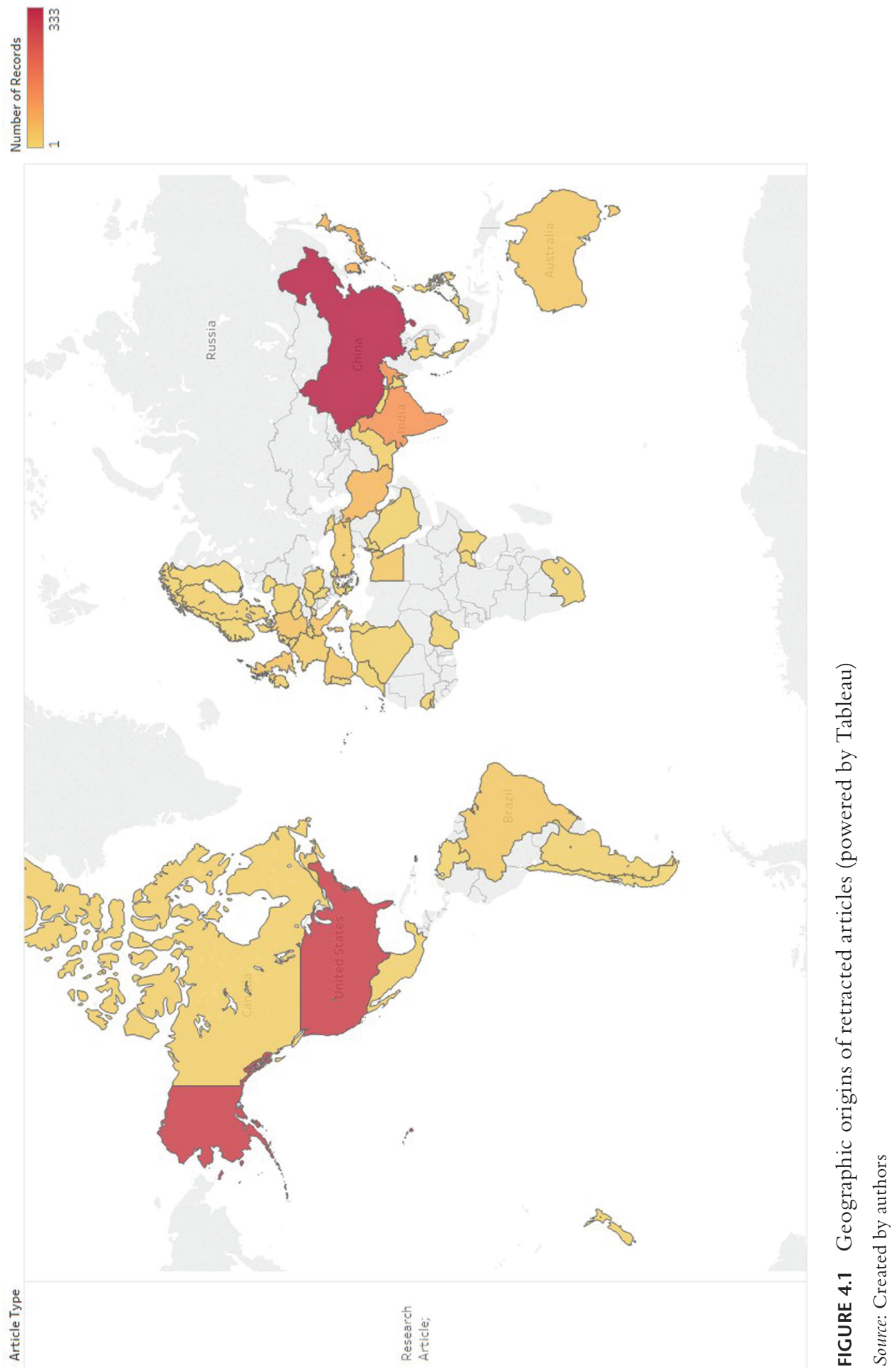
scientists fabricate or falsify data or engage in misconduct. The main reason is the pressure to publish; scientists face enormous pressure to produce a certain number of articles every year to sustain grants or receive tenure or promotion. This is especially true in the United States and the United Kingdom where the number of publications and the number of citations they receive are the main metrics used to evaluate scientific performance. This gets more complicated in countries like China where scientists are rewarded in cash for reaching a certain number of publications. These factors along with the fact that countries vary in their misconduct policies and enforcement create environments where such conduct is more prevalent (Redman \& Merz, 2008)

\section{Publications and retractions by year}

An interesting finding that we noticed in our analysis was the relative number of publications versus the amount of retractions. Whereas the annual number of publications from 2010 on that are retracted in later years stays stable, with approximately 260 publications per year (in our dataset), the number of retractions of previously published papers increases every year (see Figure 4.2). Some of the reasons for the increasing number of retractions per year can be attributed to the fact that in today's connected environment, data checking and plagiarism can be checked much faster and errors can be more easily communicated to editors who, in turn, can issue retractions that are posted to journals' online sites at increasing rates. This quicker turnaround process can be seen in the decreasing time it takes for papers to be retracted (see Table 4.1).

We also looked at the time gap between publication to retraction and calculated the average number of years that it takes. As can be seen in Table 4.1, the time gap is indeed decreasing. While in 2010 the average amount of time it took to retract articles was 2.7 years, in 2014 it went down to 1.1 year. This is a very encouraging finding that means that faulty research is taken out of circulation much faster than it used to. In the medical and biomedical arenas where discoveries can influence future studies as fast as they are reported, it is crucial to remove fraudulent research as soon as possible so as to avoid any harm to patients or the general public.

\section{Reasons for retraction}

We created a word cloud out of the text of "reasons for retraction", one of the data fields provided by Retraction Watch. In a word cloud, the size of the word or phrase is determined by the number of times it appears. The more times it appears, the bigger it becomes. In the word cloud depicted in Figure 4.3, it is evident that the most recurring reasons for retractions in our dataset of medical and biomedical articles are investigation by journal/publisher. An investigation on its own is not a reason for retraction, but looking at the phrases depicted in this word cloud we see that plagiarism, manipulation of images, errors in data, misconduct by author, 


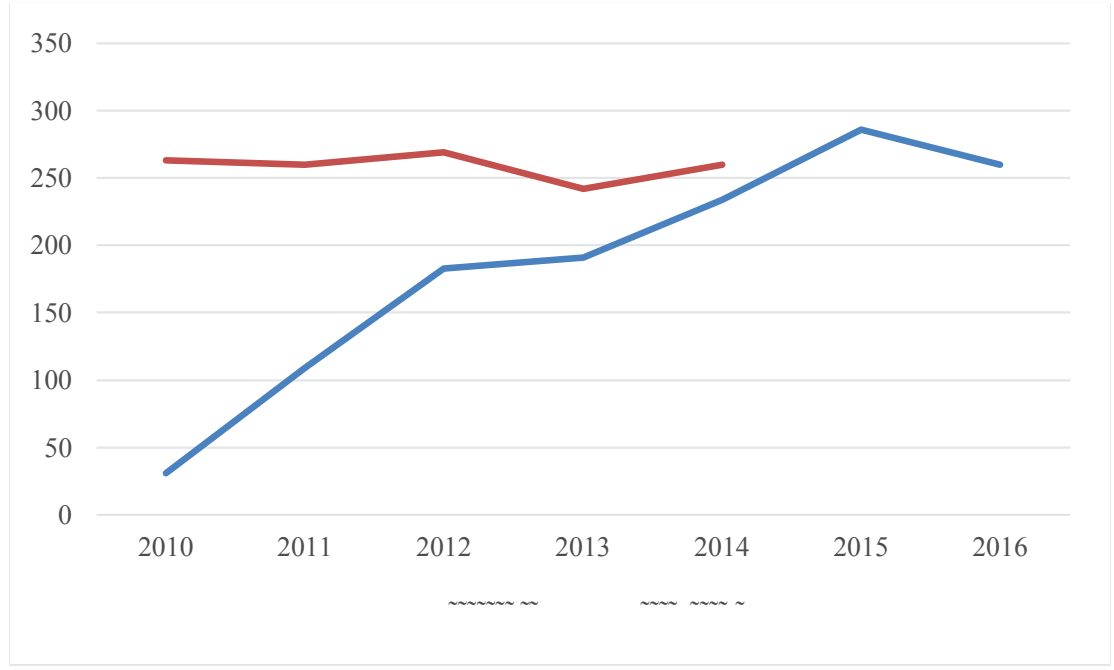

FIGURE 4.2 Yearly publication of retracted articles and retractions Source: Created by authors

TABLE 4.1 The average number of years to retract by year of publication

\begin{tabular}{lll}
\hline Year & Number of publications & Average number of years to retract \\
\hline 2010 & 263 & 2.67 \\
2011 & 260 & 2.15 \\
2012 & 269 & 1.87 \\
2013 & 242 & 1.51 \\
2014 & 260 & 1.07 \\
All years & 1294 & 1.86 \\
\hline
\end{tabular}

falsification of data, and fake peer review are dominant reasons. Duplication of article and image/s that are also dominant usually refers to authors that recycle their papers and submit the same materials to several journals. This is a conduct that every beginner researchers knows is not allowed. When submitting an article to a journal, one of the questions an author must confirm and testify to is the originality of the submission, which means that the paper was not submitted anywhere else. An author that recycles the same materials in order to game the publication process is deliberately breaking the ethical rules of scientific publishing.

Another interesting aspect in this word cloud is the number of times retractions due to data-related issues appear. Note the size of phrases such as "fabrication of data", "errors in data", "unreliable data", "issues about data", "duplication of data" and others. This means that there is a large number of publications that were taken out of the scientific literature due to severe issues with the reported 


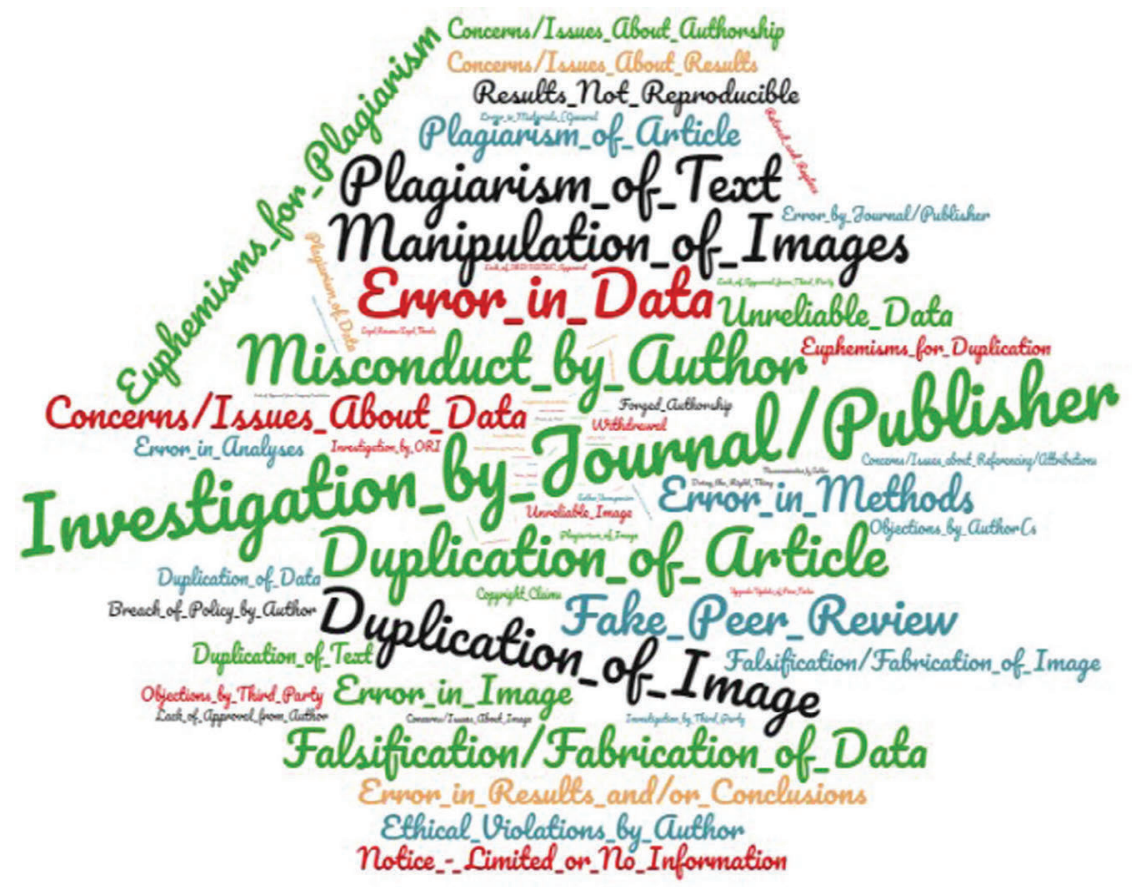

FIGURE 4.3 The word cloud of the reasons for retraction

Source: Created by authors

data. Now, although in other areas of scholarly communications, data-related issues are grave, in the medical and biomedical arenas these issues are more severe mainly because research in these disciplines relate directly to medical treatments, procedures, and drugs prescribed to patients. In addition, falsified medical data can mislead the public and cause real physical harm to people.

\section{Major journals}

In our dataset, there were 740 journals listed. Interestingly, $2 \%$ of them are responsible for $20 \%$ of all retractions. Table 4.2 lists the journals with the largest number of retracted articles in the medical and biomedical arena. While PLoS One and The Journal of Biomedical Chemistry are the journals with the highest retracted articles in the years we cover in our dataset, Tumor Biology is worth expanding on. In 2017, Tumor Biology retracted over 107 papers because of fake peer review, which means that the author faked the review either by inventing an external expert or providing a real expert but writing the review him/herself (McCook, 2017; Tumor Biology-Retraction Watch, n.d.). The magnitude of the amount of retractions in one journal resulted in the journal being removed from Web of Science and is no longer indexed in the database. The sheer number of retracted articles in 
TABLE 4.2 List of journals with most retractions before 2017

\begin{tabular}{ll}
\hline Journal title & Number of retractions \\
\hline PLoS One & 40 \\
The Journal of Biological Chemistry & 40 \\
Immunopharmacology and Immunotoxicology & 19 \\
Molecular Biology Reports & 18 \\
Proceedings of the National Academy of Sciences of the United & 16 \\
States of America & \\
The Journal of Neuroscience & 16 \\
Tumor Biology & 16 \\
Archives of Biological Sciences & 12 \\
Diagnostic Pathology & 12 \\
European Journal of Medical Research & 12 \\
Nature & 11 \\
Asian Pacific Journal of Tropical Medicine & 9 \\
BioMed Research International & 8 \\
Molecular Cell & 8 \\
Biochemical and Biophysical Research Communications & 7 \\
Cell & 7 \\
\hline
\end{tabular}

that one journal due to fake peer review indicates a systematic neglect of ethical standards that are at the core of any reputable journal. In this case, a large journal such as Tumor Biology completely neglected their responsibility while allowing over 100 papers to be published based on fraudulent peer review.

\section{Major publishers}

Our specific dataset contains articles published by 136 publishers (see Figure 4.4). Out of those, 13 publishers (or 10\%) are responsible for more than $69 \%$ of the retractions. Figure 4.4 features the top publishers, among them are Elsevier, Springer, Wiley, and Taylor \& Francis. Although Nature merged with Springer, in our dataset they are listed separately because of the timing of the merger. It is not surprising that these publishers are at the top of the list since these are publishers that specialize in the medical and biomedical fields. Despite Elsevier showing as the top of publishers retracting articles in these scientific areas it should be mentioned that Elsevier is the largest publisher in the medical and biomedical arenas with over 2,000 journals dedicated to these disciplines. Springer Nature has 1,446 journals, Wiley 822, and Taylor \& Francis 812 journals in these disciplines (data from Scopus).

\section{Citations}

Citations are considered the gold standard of scientific impact. Tenures, promotions, and funding are based on the number of publications and the number of 


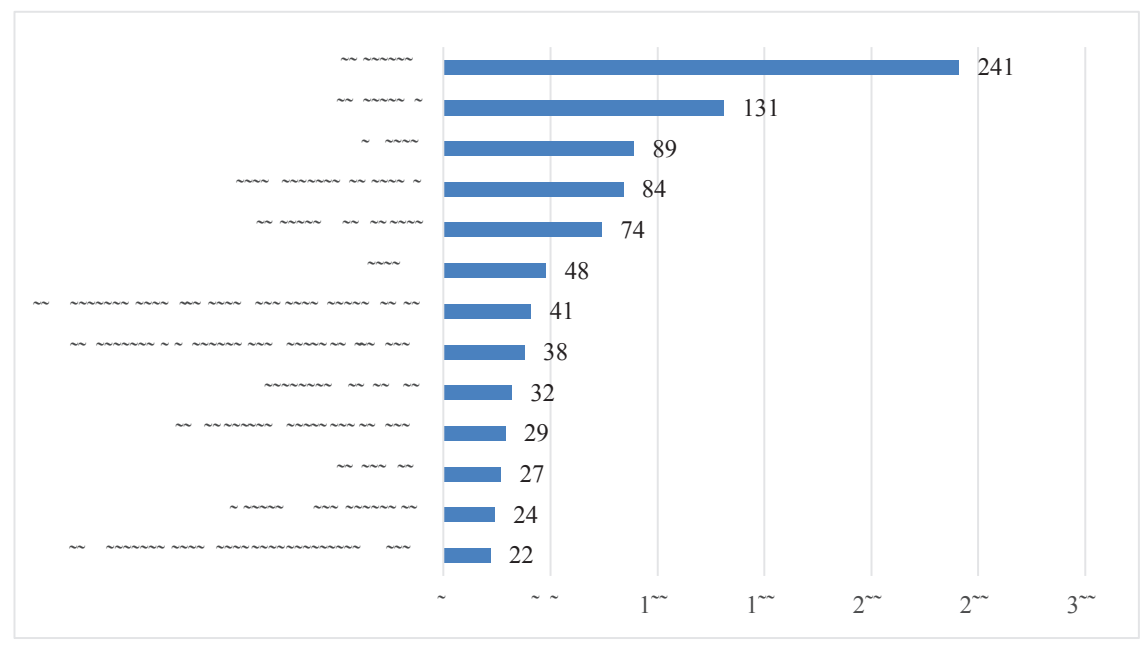

FIGURE 4.4 Publishers with the highest numbers of retracted articles Source: Created by authors

citations they receive coupled with the prestige of the journal in which they are published. Therefore, for any researcher, they are by far the most important metrics since they determine the fate of one's career and reputation. It is therefore understandable that the pressure to publish is great and researchers are aware of the number of citations their articles receive. Anyone who heard the phrase "Publish or Perish" (attributed in the academic context to Logan Wilson (Garfield, 1996) knows that researchers are under an enormous pressure to publish (Neill, 2008, 2008; Nygaard, 2017). This pressure was also blamed for the increasing amount of plagiarism and other misconduct in the academic arena (Nygaard, 2017; Rawat \& Meena, 2014). Our dataset allowed us to use Scopus to track pre- and post-retraction citations because we had the dates of the original article publication and the retraction notice. While pre-retraction citations are acceptable, post-retraction citations are disturbing since they indicate that an article that has been pulled out of the literature still receives citations, i.e., academic acknowledgment after it was flagged as fraudulent. Table 4.3 illustrates the pre- and post-retraction citations by publication year. The citations data in this chapter were collected in February 2019. It should be noted that according to citations regulations, even if an article mentions a retracted paper in a negative way it still has to cite it, which means that the faulty paper continues to accumulate academic impact despite its retraction status.

\section{Readership}

The ability to track the number of times an article is read is relatively new. "Readership" is a part of a group of metrics called "altmetrics" (alternative metrics) 
TABLE 4.3 Pre- and post-retraction citations per publication year

\begin{tabular}{lccc}
\hline Year of publication & $\begin{array}{l}\text { Pre-and post-retraction } \\
\text { citations }\end{array}$ & $\begin{array}{l}\text { Citations before } \\
\text { retraction }\end{array}$ & $\begin{array}{l}\text { Citations after } \\
\text { retraction }\end{array}$ \\
\hline 2010 & 6,819 & 4,587 & 2,232 \\
2011 & 6,104 & 3,650 & 2,454 \\
2012 & 4,063 & 2,266 & 1,797 \\
2013 & 2,858 & 1,570 & 1,288 \\
2014 & 2,145 & 986 & 1,159 \\
All years & 21,989 & 13,059 & 8,930 \\
\hline
\end{tabular}

TABLE 4.4 Mendeley reader counts of the retracted articles

\begin{tabular}{lcclc}
\hline Year of publication & $\begin{array}{l}\text { Number of } \\
\text { publications }\end{array}$ & $\begin{array}{l}\text { Number of } \\
\text { readers }\end{array}$ & $\begin{array}{l}\text { Average number } \\
\text { of readers }\end{array}$ & $\begin{array}{l}\text { Article with most } \\
\text { readers }\end{array}$ \\
\hline 2010 & 263 & 7,790 & 29.6 & 328 \\
2011 & 260 & 8,896 & 34.2 & 388 \\
2012 & 269 & 8,226 & 30.6 & 752 \\
2013 & 242 & 12,414 & 51.3 & 4,130 \\
2014 & 260 & 4,814 & 18.5 & 265 \\
All years & 1,294 & 42,140 & 32.6 & 4,130 \\
\hline
\end{tabular}

aimed to examine the manner by which scientific literature is used beyond citations. Readership counts are available on a number of platforms, among which is Mendeley, a hybrid platform that serves as a reference manager and also a social network where scholars can save and share articles. The readership count in Mendeley can relate to citations in some ways. First, users on Mendeley are mostly scholars and students and therefore the network is an academic one rather than an open social one, although anyone can join. Significant, medium-strength correlations were found by several studies (Costas, Zahedi, \& Wouters, 2015; Haustein, 2016; Li \& Thelwall, 2012) between readership and citation counts, indicating there is a partial overlap between readers and citers. The correlations are even stronger for medical fields (Thelwall, 2016).

In our dataset, $91 \%$ of retracted articles $(1,178)$ had Mendeley reader counts. We also found that 1,091 (84\%) of all retracted articles in the dataset had both Scopus citations and Mendeley reader counts. Table 4.4 displays the total and average reader counts per year of publication. Overall, the number of readers is quite high but the most noticeable year is 2013 where we see a significant rise in the number of reads. The reason lies in two articles published that year in Nature (see case of Haruko Obokata) that were retracted due to falsification and misconduct and created quite a stir in the scientific world. These two papers alone were the two most read articles, with 4,130 and 2,066 readers, and have been 
cited 166 and 85 times respectively. Both these articles also received 78 and 40 citations post-retraction and despite the scandal that led to the suicide of one of the authors.

\section{Social media}

In order to account for the social impact of retracted articles, we used two platforms that track social media mentions: Altmetric.com and PlumX. When an article is published, it is a given a unique number (DOI), that can be searched for and discovered in search engines. Both PlumX and Altmetric.com platforms are well known for tracking social media mentions of academic publications through a unique number called DOI (Distinct Object Identifier) and are able to point to mentions on social media channels such as Twitter, Facebook, Wikipedia, and others. Altmetric.com and PlumX track social media mentions in slightly different ways. For example, when scanning blogs and news, Altmetric.com tracks Wikipedia in English only, while PlumX tracks Wikipedia in Swedish as well, or when counting Facebook mentions Altmetric.com scans posts on public Facebook pages, while PlumX reports likes, shares, and comments combined. Other research found that Twitter mentions of scientific publications is usually the most meaningful compared to other social media outlets (Thelwall, Haustein, Larivière, \& Sugimoto, 2013). However, tracking overall social media mentions is still considered one of the best ways to gauge public reactions to scientific literature. Table 4.5 summarizes the number of times retracted articles where showing on social and news media. As can be seen from the table, Altmetric.com was able to identify 456 articles that were mentioned on Twitter while PlumX identified 305 articles. It is clear that Twitter is by far the most dominant social media channel used to share and comment on articles, with over 7,000 mentions identified by Altmetric.com and close to 6,000 on PlumX. Facebook is the second most popular platform on which these retracted articles were shared, discussed, and commented on, with over 10,000 appearances on PlumX. In addition, since we were examining retracted medical and biomedical papers it is not surprising that news media covered quite a few of them as well. Altmetric.com was able to identify 81 retracted articles in the news media. These numbers are very much in line with other research that has shown that most people in the United States consume medical and scientific information from social media (Greenwood et al., 2016; NW, Washington, \& Inquiries, 2018). The highest number of social and news media mentions was tracked for the 2013 article "Primary Prevention of Cardiovascular Disease with a Mediterranean Diet", which was published in the New England Journal of Medicine in 2013. This article was retracted due to the study design and the fact that a significant amount of people dropped off the control groups, which basically skewed the results. Although the same article was re-published later with a new analysis, the impact of the retraction continues to steer controversy today. So far (August 2019), this retracted article gained 195 news articles; over 47,000 shares, likes, and comments on 
60 Judit Bar-llan \& Gali Halevi

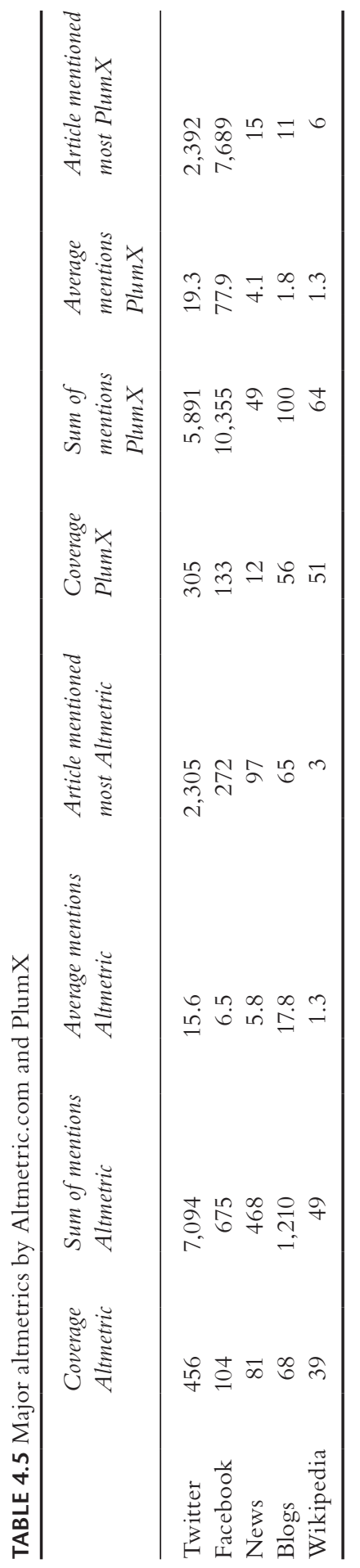


Facebook; and over 1,600 tweets and retweets, and the debate continues. To view this article dashboard with the social media comments, please visit https:// plu.mx/judit/a/--LPrDZbZGFIxEcIgDOzjbhPj1--P4QGWWC7IKS-Um0/.

\section{Most impactful retracted articles}

In this section, we discuss the articles in our dataset that were cited the most (preand post-retraction), the ones that were read the most, and those that received the most tweets as tracked by Altmetric.com and PlumX.

\section{Most cited retracted article before and after retraction}

Estruch, R., Ros, E., Salas-Salvadó, J., Covas, M. I., Corella, D., Arós, F., . . \& Lamuela-Raventos, R. M. (2013). Primary prevention of cardiovascular disease with a Mediterranean diet. New England Journal of Medicine, 368(14), 1279-1290.

This article was considered a breakthrough in cardiovascular research pointing to the benefits of an olive oil-based diet to improve cardiovascular conditions. However, faults in the study design and reported findings by the authors who wrote "Because of irregularities in the randomization procedures, we wish to retract the article" (see retraction notice). Although the data was reanalyzed and the article later republished, the debate around the actual benefits of the Mediterranean Diet continues to this day.

\section{Most cited article before retraction}

Dunoyer, P., Schott, G., Himber, C., Meyer, D., Takeda, A., Carrington, J. C., \& Voinnet, O. (2010). Small RNA duplexes function as mobile silencing signals between plant cells. Science, 1185880.

This article was considered groundbreaking due to its claim that small RNAs found in plants can function as a defense against viral attacks. The article was retracted six years after publication due to image duplication and manipulations that the editors deemed as deliberate and that could not have been a result of a mistake. Interestingly, all the authors except the main author agreed to retract the article (Berg, 2016). Since the time gap between publication and retraction was six years, the article gained a large number of citations pre-retraction.

\section{Most cited post-retraction}

Séralini, G. E., Clair, E., Mesnage, R., Gress, S., Defarge, N., Malatesta, M., . . \& De Vendômois, J. S. (2012). Long term toxicity of a Roundup herbicide and a Roundup-tolerant genetically modified maize. Food and Chemical Toxicology, 50(11), 4221-4231.

This article was the first to point to GMO (genetically modified organisms) food as being toxic to human health and the source of several cancer types. The 
study was attacked by scientists who pointed to several crucial points in the study design and analytics and was retracted that same year. However, the study sparked serious political debate by groups of anti-GMO activists who claimed that the retraction was invalid and driven by politics rather than science. To this day, the debate continues, with several recent news media articles published on the issue of GMO food safety. To see all news and other discussions, please visit https://plu.mx/judit/a/-BV5QqinvoXUlWNq7GKRdJQgWyZMb1bGDBtTn ZaZRVU/.

\section{Most read and most tweeted (Altmetric.com and PlumX)}

Obokata, H., Wakayama, T., Sasai, Y., Kojima, K., Vacanti, M. P., Niwa, H., . . \& \& Vacanti, C. A. (2014). Stimulus-triggered fate conversion of somatic cells into pluripotency. Nature, 505(7485), 641.

This article was the center of a scandal that resulted in the suicide of one of the authors. A group of Japanese researchers claimed that they found a way to create pluripotent stem cells, which are able to give rise to almost any other cell type by using physical stimulus. As can be imagined, the impact of such a discovery, if it was true, would have been universally life changing as a potential cure for any disease known to mankind. However, this study was a result of falsified experiments and data. This article was retracted that same year but still read and shared over 12,000 times and mentioned on social media over 2,400 times. To see a complete overview of this article, including social and news media mentions, please visit https:// plu.mx/judit/a/-XiygtWNXexZCjaHt_16yDTcT9zIKiNbPqUL4-3V-Tw/.

\section{Highly impactful retracted articles - some recent examples}

\section{Data analytics and study design issues}

Séralini, G. E., Clair, E., Mesnage, R., Gress, S., Defarge, N., Malatesta, M., . . . \& De Vendômois, J. S. (2012). Long term toxicity of a Roundup herbicide and a Roundup-tolerant genetically modified maize. Food and Chemical Toxicology, 50(11), 4221-4231.

In 2012, a group of French scientists published an article regarding the harmfulness of genetically modified maize. The article's conclusions suggested that GMO foods could cause all types of cancer, proving it through a two-year experiment in mice. The article titled "Long term toxicity of a Roundup herbicide and a Roundup-tolerant genetically modified maize" created a media storm, calling all GMO foods to be avoided due to serious health hazards, which quickly turned into thousands of international social media shares and heated discussions. The article was retracted after a series of letters to the editors pointed out the inadequacy of the study design, the data analysis and interpretation of results pointing out its invalidity, and that it should not be used to inform health policy or public health recommendations. However, this article and the results reported 
in it prevail in both the scientific literature and in the social media and public news arenas. Despite the 2012 retraction, our data shows that high citation rate to this article still persists through 2018 (see Table 4.6, third row). According to Scopus metrics, this article is in the 99th percentile of citations in its field, with a total of 181 citations tracked in Scopus until very recently. The social and news media attention to this article and its results are much higher. PlumX tracked nearly 8,000 likes, shares, and comments on Facebook; over 1,100 mentions on Twitter; and more than ten mentions in the news and in blogs. We found that the article is mentioned, despite its flaws, in contexts of health and nutrition recommendations (see for example Templeton, 2019; Ten Scientific Studies Prove that Genetically Modified Food Can Be Harmful To Human Health, 2018). It should be noted that the retracted article was republished as-is (without another round of peer review) in Environmental Sciences Europe in 2014. The republished article also received considerable news and social media attention, readers on Mendeley and citations on Scopus.

\section{Misconduct, fraudulent reporting}

Obokata, H., Wakayama, T., Sasai, Y., Kojima, K., Vacanti, M. P., Niwa, H., . . \& \& Vacanti, C. A. (2014). Stimulus-triggered fate conversion of somatic cells into pluripotency. Nature, 505(7485), 641.

In 2014, a group of Japanese scientists published two related high-profile research papers on a breakthrough in stem cell research that was published in Nature. The main discovery, according to them was that they managed to prove that physical stimulus could transform adult cells into pluripotent stem cells that are able to give rise to almost any other cell type. The acronym STAP (stimulustriggered acquisition of pluripotency), which was coined by this group, became instantly famous. The significance of this research is that before this research was published, scientists assumed that this could only be achieved by genetic manipulation. If this research was true, the consequence would have been a gigantic step toward the elimination of genetically inherited diseases for example. However, five months after the publication of the paper and following an investigation of the scientists by their institution, it was retracted due to misconduct. The scientists involved were accused of poor data management and record-keeping, manipulation of images and figures, and more. Because of the enormity of the so-called discovery, the retraction gained an enormous amount of scientific and public attention (see last row in Table 4.6) to the point where in 2014 a co-author of these papers committed suicide, another suffered a stroke, and a third was hospitalized for depression (Goodyear, 2016). Despite the fact that this article was relatively quickly retracted, the social media attention to this article persisted years after. There are over 2,000 shares on Twitter and numerous shares on Facebook, most of which just link to the article without mentioning the scandal behind it or the fact that it was retracted years prior. That said, some claim that it was social media that had a major role in exposing this article (Diaz, 2018). The 
64 Judit Bar-Ilan \& Gali Halevi

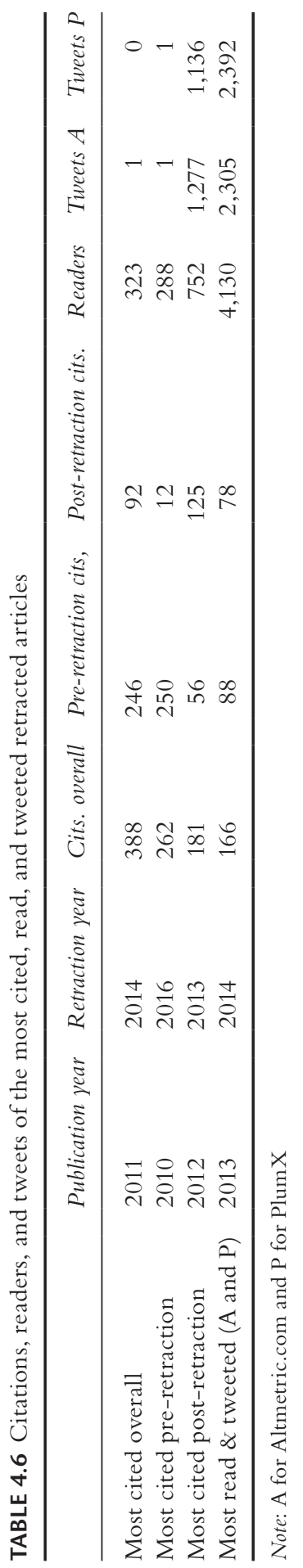


scientific impact viewed through 167 citations tracked by Scopus are mostly negative. Many of the articles discuss aspects of scientific misconduct, reproducibility issues, and ethics in genetic research. The same lead author, with a large number of overlapping co-authors, published another paper in Nature in the same year: "Bidirectional Developmental Potential in Reprogrammed Cells with Acquired Pluripotency”, which was retracted for similar reasons in 2014. She also set up a website after the two articles were retracted (STAP HOPE PAGE, n.d.) trying to convince the public of her methods. The website has not been updated since 2016. She also published a book in Japanese in 2016 on the STAP-cell scandal (Knoepfler, 2016).

\section{Reproducibility issues}

Yi, P., Park, J. S., \& Melton, D. A. (2013). Betatrophin: A Hormone that Controls Pancreatic $\beta$ Cell Proliferation. Cell 53(4), 747-757.

In 2013, a group of Harvard scientists published a high-profile paper that suggested that they found a new hormone that could increase the amount of beta cells, which in turn can cure type 1 diabetes. The article was published in one of the most prestigious scientific journals Cell and retracted in 2017 due to the fact that no one, including the scientists themselves, could reproduce the results of their experiments. Although no ethical issues rose in the review and retraction processes, the topic of reproducibility should be paid attention. The progress of science depends on the ability to reproduce experimental results and, through that, find ways to build upon them and advance to the next level of discovery. This article is a good example of a scientific breakthrough that never was due to the growing problem of reproducibility, and although not mentioned as much in the news or social media outlets, was and still is heavily cited, with 30 citations in 2018 alone. If results cannot be reproduced, the science ends there. According to a Nature survey (Baker, 2016), 70\% of researchers have tried and failed to reproduce another scientist's experiments and more than 50\% failed to reproduce their own experiments. This is an enormous challenge to the overall trust in the entire scientific process. The survey found that the main reason these experiments cannot be reproduced is that scientists selectively report on results that support their hypothesis in order to publish faster and secure funding for example. Yet the crisis of reproducibility (as named by the article) is heightened because journals are reluctant to make this problem public by publishing negative replications and "In fact, several respondents who had published a failed replication said that editors and reviewers demanded that they play down comparisons with the original study" (p. 454).

\section{Conclusions}

In 2012, the National Academy of Sciences in the United States published a review of 1,047 articles in biomedical and life sciences indexed in PubMed (Fang 
et al., 2012). This study found that only $21.3 \%$ of these articles were retracted because of honest mistakes (as opposed to deliberate fraud), whereas $67.4 \%$ of retractions were due to misconduct, including fraud, plagiarism, and duplications. Named the "retraction epidemic", the study points to the fact that the number of retractions in these fields have increased tenfold since 1975. On the one hand, this is a positive development since it does demonstrate the selfregulation of the scientific publication process in which articles do not cease to be scrutinized after publication and once found to be fraudulent are removed from the literature. On the other hand, it is still worrying that such articles manage to escape the watchful eye of reviewers and get published in highly reputable journals such as Nature, The Lancet, Cell, and more.

In this chapter, we examined a dataset of retracted articles in the medical and biomedical fields published between 2010 to 2014 and retracted due to numerous reasons but mainly because of fraud and misconduct. Data and images manipulations, unethical experiments, and misleading analysis and conclusions have led to massive retractions across journals. As demonstrated, the time gap between publication and retraction remains problematic. Although this time gap is seen to get shorter in time, averaging a little over a year now as opposed to ten years in the past, it is still enough for these articles to influence the medical and biomedical scientific process on many levels. First, these articles are cited in the scientific literature, which means that their findings are being applied in studies. One should not forget that in this area, studies mean patients, enrolled in clinical trials or being administered procedures or drugs. Second, these articles, and especially those that claim some type of breakthrough, are heavily mentioned in the social and news media, which reaches hundreds of thousands of people quickly and without barriers.

After being retracted, these articles are seen to be cited and publicly discussed on these channels. This is the most concerning phenomenon of retracted articles. This is probably due to their availability as Open Access content, free for all to read, or due to versions of the articles such as pre- or post-print versions that circulate in freely available repositories. And while public sharing and discussion of retracted articles might not raise a brow, considering the fact that people might misinterpret or not even know a certain article was retracted, continuous citations are certainly worrying. Despite the fact that some citations may prove to be negative ones, meaning that the authors mention the article to demonstrate its fraudulence, our previous research showed that many of the citations are positive and cite retracted research as valid (Bar-Ilan \& Halevi, 2018).

So, what can be done? Readers must be alert. Whether scientific or lay persons, anyone who relies on published articles or news regarding studies in the medical and biomedical arenas must scrutinize their content. For the lay person things to watch for are sponsorship or funding source. Every researcher must reveal his/her funding source or study sponsor. If an organization or company is the study sponsor, one should carefully and cautiously assess the study to discover whether or not it was written to support certain economic interests. Scientists, 
who are well versed in the terminology, the study design, and data collection method should scrutinize the article for data and image integrity as well as analysis and conclusions.

According to COPE (Promoting integrity in research and its publication | Committee on Publication Ethics: COPE, n.d.) guidelines, retracted articles should not be removed but be clearly labeled as retracted. However, the guidelines do not say that retracted articles should be freely available on the publisher's website. We found many retracted articles to be freely accessible, whereas other articles in the same journal and issue are behind paywall. Allowing these to be open and freely available increases the chances of people who do not have access to paid-for content to read, save, share, and promote them on social media.

In addition, we recommend that publishers remove all retracted articles from their journals' websites so readers will not have access to their full text. The fact that retracted articles can be found in their full text for free aggravates the problem. Retracted research should not be found anywhere on journals' sites. Although it is clear that publishers cannot address preprints available on repositories, they can and should address faculty publications' availability on their own sites.

Just like with other forms of fake news, apply caution and do your own investigation. One newly available comprehensive and searchable source is the Retraction Watch Database. Acting on fraudulent, false medical and biomedical literature can cost you your health.

\section{Note}

1 Newton, "Letter from Sir Isaac Newton to Robert Hooke"

\section{References}

Almeida, R. M. V., de Albuquerque Rocha, K., Catelani, F., Fontes-Pereira, A. J., \& Vasconcelos, S. M. (2015). Plagiarism allegations account for most retractions in major Latin American/Caribbean databases. Science and Engineering Ethics, 1-10.

Baker, M. (2016). 1,500 scientists lift the lid on reproducibility. Nature News, 533(7604), 452. https://doi.org/10.1038/533452a

Bar-Ilan, J., \& Halevi, G. (2017). Temporal characteristics of retracted articles: Research in progress. ISSI 2017-16th International Conference on Scientometrics and Informetrics, Conference Proceedings, 650-655. Retrieved from www.scopus.com/inward/ record.uri?eid=2-s2.0-85036606736\&partnerID $=40 \& \mathrm{md} 5=7$ be 4a 5 ef9ec4266667ff 4 8734340 dd 63

Bar-Ilan, J., \& Halevi, G. (2018). Temporal characteristics of retracted articles. Scientometrics, 116(3), 1771-1783.

Berg, J. M. (2016). Retraction. Science, 354(6309), 190-190. https://doi.org/10.1126/ science.aai9397

Biagioli, M., Kenney, M., Martin, B., \& Walsh, J. P. (2018). Academic misconduct, misrepresentation and gaming: A reassessment. Research Policy, 48(2), 401-413

Bozzo, A., Bali, K., Evaniew, N., \& Ghert, M. (2017). Retractions in cancer research: A systematic survey. Research Integrity and Peer Review, 2(1), 5. 
Broad, W. J. (1983, June 14). Notorious darsee case shakes assumptions about science. The New York Times. Retrieved from www.nytimes.com/1983/06/14/science/notoriousdarsee-case-shakes-assumptions-about-science.html

Budd, J. M., Sievert, M., \& Schultz, T. R. (1998). Phenomena of retraction: Reasons for retraction and citations to the publications. Journal of the American Medical Association, 280(3), 296-297. https://doi.org/10.1001/jama.280.3.296

Budd, J. M., Sievert, M., Schultz, T. R., \& Scoville, C. (1999). Effects of article retraction on citation and practice in medicine. Bulletin of the Medical Library Association, 87(4), 437-443.

Cokol, M., Ozbay, F., \& Rodriguez-Esteban, R. (2008). Retraction rates are on the rise. EMBO Reports, 9(1), 2-2. https://doi.org/10.1038/sj.embor.7401143

Corbyn, Z. (2012). Misconduct is the main cause of life-sciences retractions. Nature, 490(7418), 21.

Costas, R., Zahedi, Z., \& Wouters, P. (2015). Do "altmetrics" correlate with citations? Extensive comparison of altmetric indicators with citations from a multidisciplinary perspective. Journal of the Association for Information Science and Technology, 66(10), 20032019. https://doi.org/10.1002/asi.23309

Diaz, A. (2018, March 3). Science and social media. Retrieved January 22, 2019, from Northwest Jammin website: https://medium.com/northwest-jammin/science-andsocial-media-9e33ba90e04d

Facts about the Measles Outbreak. (2015, February 2). The New York Times. Retrieved from www.nytimes.com/interactive/2015/02/02/us/measles-facts.html

Fanelli, D., Costas, R., Fang, F. C., Casadevall, A., \& Bik, E. M. (2017). Why do scientists fabricate and falsify data? A matched-control analysis of papers containing problematic image duplications. BioRxiv, 126805. https://doi.org/10.1101/126805

Fang, F. C., \& Casadevall, A. (2011). Retracted science and the retraction index. Infection and Immunity, 79(10), 3855-3859.

Fang, F. C., Steen, R. G., \& Casadevall, A. (2012). Misconduct accounts for the majority of retracted scientific publications. Proceedings of the National Academy of Sciences, 109(42), 17028-17033.

Garfield, E. (1996). What is the primordial reference for the phrase "publish or perish". The Scientist, 10(12), 11.

Goodyear, D. (2016, February 22). The stem-cell scandal. Retrieved from www. newyorker.com/magazine/2016/02/29/the-stem-cell-scandal

Greenwood, S., Perrin, A., \& Duggan, M. (2016, November 11). Social media update 2016. Retrieved March 5, 2017, from Pew Research Center: Internet, Science \& Tech website: www.pewinternet.org/2016/11/11/social-media-update-2016/

Halevi, G., \& Bar-Ilan, J. (2016). Post retraction citations in context. Proceedings of the Joint Workshop on Bibliometric-Enhanced Information Retrieval and Natural Language Processing for Digital Libraries (BIRNDL), Newark, NJ, 23-29.

Haustein, S. (2016). Grand challenges in altmetrics: Heterogeneity, data quality and dependencies. Scientometrics, 108(1), 413-423. https://doi.org/10.1007/s11192-016-1910-9

Inoue, Y., \& Muto, K. (2016). Noncompliance with human subjects' protection requirements as a reason for retracting papers: Survey of retraction notices on medical papers published from 1981 to 2011. Accountability in Research, 23(2), 123-135. https://doi.org/ 10.1080/08989621.2015.1069713

Knoepfler, P. (2016, March 31). Haruko Obokata (小保方 晴子) launches new website with STAP claims. Retrieved July 11, 2019, from The Niche website: https:// ipscell.com/2016/03/haruko-obokata-\%e5\%b0\%8f\%e4\%bf\%9d\%e6\%96\%b9-\%e6\% 99\%b4\%e5\%ad\%90-launches-new-website-with-stap-claims/ 
Li, X., \& Thelwall, M. (2012). F1000, Mendeley and traditional bibliometric indicators. Proceedings of the 17th International Conference on Science and Technology Indicators, 2, 451-551. Science-Metrix and OST Montréal, Canada.

McCook, A. A. (2017, April 20). A new record: Major publisher retracting more than 100 studies from cancer journal over fake peer reviews. Retrieved February 2, 2019, from Retraction Watch website: https://retractionwatch.com/2017/04/20/new-recordmajor-publisher-retracting-100-studies-cancer-journal-fake-peer-reviews/

Neill, U. S. (2008). Publish or perish, but at what cost? The Journal of Clinical Investigation, 118(7), 2368-2368.

Nicholas, D., Watkinson, A., Jamali, H. R., Herman, E., Tenopir, C., Volentine, R., . . Levine, K. (2015). Peer review: Still king in the digital age. Learned Publishing, 28(1), $15-21$.

Noyori, R., \& Richmond, J. P. (2013). Ethical conduct in chemical research and publishing. Advanced Synthesis \& Catalysis, 355(1), 3-9.

NW, 1615 L. St, Washington, S. 800, \& Inquiries, D. 20036 U.-419-4300 | M.-4194372 | M. (2018, March 20). Science-related Facebook pages draw millions of followers, but only about three-in-ten posts feature new scientific discoveries. Retrieved August 27, 2018, from Pew Research Center: Internet, Science \& Tech website: www.pewinternet.org/2018/03/21/the-science-people-see-on-social-media/ ps_2018-03-21_facebook-and-science_0-01/

Nygaard, L. P. (2017). Publishing and perishing: An academic literacies framework for investigating research productivity. Studies in Higher Education, 42(3), 519-532.

Promoting integrity in research and its publication | Committee on Publication Ethics: COPE. (n.d.). Retrieved July 11, 2019, from https://publicationethics.org/

Rawat, S., \& Meena, S. (2014). Publish or perish: Where are we heading? Journal of Research in Medical Sciences: The Official Journal of Isfahan University of Medical Sciences, 19(2), 87.

Redman, B. K., \& Merz, J. F. (2008). Scientific misconduct: Do the punishments fit the crime? American Association for the Advancement of Science. Science, 321(5890), 775.

Retraction Watch Database. (n.d.). Retrieved January 18, 2019, from http://retraction database.org/RetractionSearch.aspx?

STAP HOPE PAGE. (n.d.). Retrieved July 11, 2019, from STAP HOPE PAGE website: https://stap-hope-page.com/

Steen, R. G. (2010). Retractions in the scientific literature: Is the incidence of research fraud increasing? Journal of Medical Ethics, 37(4), 249-253.

Steen, R. G. (2011). Retractions in the scientific literature: Do authors deliberately commit research fraud? Journal of Medical Ethics, 37(2), 113-117.

Templeton, B. (2019, February 22). Templeton times: Cancer-linked monsanto chemical discovered in five major orange juice brands from collective evolution. Retrieved July 29, 2019, from Templeton Times website: http://templeton01436.blogspot. com/2019/02/cancer-linked-monsanto-chemical.html

Ten Scientific Studies Prove that Genetically Modified Food Can Be Harmful To Human Health. (2018, March 13). Retrieved July 29, 2019, from Global Research website: www.globalresearch.ca/ten-scientific-studies-proving-gmos-can-be-harmfulto-human-health/5377054

Thelwall, M. (2016). Interpreting correlations between citation counts and other indicators. Scientometrics, 108(1), 337-347. https://doi.org/10.1007/s11192-016-1973-7

Thelwall, M., Haustein, S., Larivière, V., \& Sugimoto, C. R. (2013). Do Altmetrics Work? Twitter and Ten Other Social Web Services. PLoS One, 8(5). https://doi. org/10.1371/journal.pone.0064841 
Tumor Biology-Retraction Watch. (n.d.). Retrieved February 2, 2019, from https:// retractionwatch.com/category/by-journal/tumor-biology/

Upi. (1982, May 20). Doctor admits filing false data and is barred from U.S. support. The New York Times. Retrieved from www.nytimes.com/1982/05/20/us/doctor-admitsfiling-false-data-and-is-barred-from-us-support.html

Williams, P., \& Wager, E. (2013). Exploring why and how journal editors retract articles: Findings from a qualitative study. Science and Engineering Ethics, 19(1), 1-11. 